\title{
TRANSFORMACIÓN DIGITAL DEL PERIODISMO IMPRESO EN EL Perú en tiempos de Pandemia
}

\author{
Digital transformation of printed journalism in Peru in \\ pandemic times
}

\section{Emiliano Paico-Zumaeta ${ }^{1}$}

\begin{abstract}
RESUMeN
Se da a conocer cómo ha sido afectado el periodismo impreso en el Perú ante la irrupción de la pandemia de la COVID-19 y las estrategias que se han realizado para afrontar la embestida del virus SARS-Cov-2. Se destaca la importancia del periodismo impreso en tiempo de pandemia, las muertes de los periodistas a consecuencia de la COVID-19, los despidos, disminuciones salariales y agresiones a periodistas; asimismo, la disminución de las ventas de los medios impresos, la publicidad y las suscripciones. Igualmente, la incursión rápida a la tecnología digital y sus efectos en la implantación del trabajo remoto y en los cambios en horarios laborales.
\end{abstract}

Palabras claves: Periodismo, COVID-19, periodistas, diarios, tecnología, digital, trabajo remoto.

\section{Abstract}

It is disclosed how printed journalism in Peru has been affected by the emergence of the COVID-19 pandemic and the strategies that have been made to deal with the onslaught of the SARS-Cov-2 virus. Highlights include the importance of pandemic-time printed journalism, the deaths of journalists as a result of COVID-19, layoffs, pay cuts and assaults on journalists; as well as print media sales, sales of print media, advertising and low subscriptions. Likewise, the rapid incursion into digital technology and its effects on the implementation of remote work and changes in working hours.

Keywords: Journalism, COVID-19, journalists, newspapers, technology, digital, remote work.

1 Estudiante de la Facultad de Ciencias de la Comunicación de la Universidad Privada Antenor Orrego.

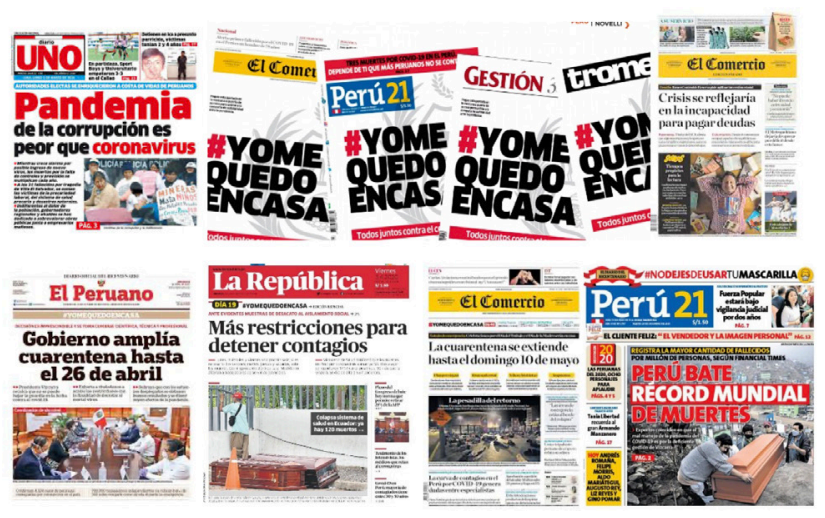

Composición de Oscar Pamo

21 esde tiempos remotos las epidemias y pandemias han sido - y continúan siendo - uno de los temibles enemigos de la humanidad, que en el transcurso de los siglos ha causado miles de millones de muertes a nivel mundial.

La pandemia de COVID-19 es una pandemia derivada de la nueva enfermedad por coronavirus 2019 (COVID-19), ocasionada por el virus SARS-CoV-2 (coronavirus del síndrome respiratorio agudo grave tipo 2) ${ }^{(1)}$ En diciembre de 2019, en Wuhan (China), apareció por primera vez el virus de la enfermedad que 
rápidamente se extendió a diferentes países del mundo, motivo el cual el 11 de marzo de 2020 la OMS (2) la reconoció como una pandemia.

La pandemia de la Covid-19 ha llevado a una crisis mundial originando una terrible catástrofe sanitaria, humanitaria, social y económica y, el Perú no ha escapado a ello.

A nivel mundial, hasta el 14 de diciembre de 2020 se ha reportado 1,6 millones de personas muertas como consecuencia de la Covid-19. De esta cifra, 290130 muertes han sucedió en Asia (lugar donde por primera apareció el virus); 474800 en Europa; y 785400 en América.

En el Perú, según el Instituto Nacional de Salud y Centro Nacional de Epidemiología, Prevención y Control de Enfermedades MINSA (3), hasta el jueves 24 de diciembre, de un total 1003982 de personas contagiadas, han fallecidos 37 3I7.

Al igual que en muchos países del mundo, en el Perú la pandemia de la Covid-19 ha castigado a todos los sectores de la población, infectando y diezmando a profesionales, administrativos, empleados, comerciantes, desempleados y otros. Pero las cifras de defunciones de periodistas son verdaderamente alarmantes, ocupando el segundo lugar después del gremio médico. Algunos de los periodistas han fallecido tras el contagio de la enfermedad cumpliendo labores informativas sobre la pandemia del coronavirus o ejecutando otro trabajo. Asimismo, muchos hombres de la prensa peruana han sido destituidos de sus centros de trabajo o se les ha disminuido su sueldo.

Por otra parte, la pandemia de la Covid-19, ha exigido a los periodistas peruanos a dar un giro copernicano en su trabajo, incursionando aceleradamente a la tecnología digital con redacciones móviles y de teletrabajo; asimismo, modificando los horarios de trabajo con el objetivo de informar oportuna y adecuadamente, en la manera que era posible, todo lo relacionado a la pandemia.

Las reflexiones antes mencionadas han motivado a realizar el presente trabajo con el propósito de analizar la evolución del periodismo escrito del Perú en tiempo de pandemia; es decir, investigar de qué manera ha sido afectado el periodismo escrito y qué estrategias ha empleado para afrontar la pandemia; resultados que estamos presentando en este artículo.

COYUNTURA DEL PERIODISMO IMPRESO EN TIEMPOS DE PANDEMIA

\section{Influencia del gobierno sobre el periodismo}

Desde la irrupción de la pandemia de la Covid-19, los gobiernos de los diferentes países se comprometieron, con la colaboración de los médicos y de los periodistas, a guiar a las poblaciones a luchar contra una de las peores epidemias de los últimos tiempos, teniendo que fundamentar sus decisiones en la escasa y contradictoria información de esta nueva enfermedad infecciosa. Labor difícil, con desenlaces imprevistos y resultados inimaginables.

En muchos países, incluido el nuestro, esta zozobra aumentó la preferencia de los mandatarios a intentar controlar cada parte del flujo de información y callar las voces indeseadas.

Desde el inicio de la pandemia, el mundo fue testigo de diversos casos en los que las autoridades implantaron medidas, leyes o 
decretos especiales para limitar los derechos de los hombres de prensa y los medios de comunicación, así como el libre flujo de información. Situación que el periodismo peruano lo ha palpado de cerca.

Las disposiciones transcurrieron desde la imposición a publicar solamente información suministrada por los gobernantes hasta el bloqueo de páginas web; así también como restringir el acercamiento a la información oficial y sancionar a los periodistas culpados de difundir las fake news.

En Perú, el gobierno no sinceró las cifras de los muertos en los cinco primeros meses de la pandemia. La exigencia del pueblo y con la colaboración de algunos medios de comunicación, "obligó" al gobierno sincerar las cifras, lo que se hizo a través del Ministerio de Salud. El presidente de la República acompañado de sus ministros, diariamente daba conferencias de prensa pero las cifras de muertos que reportaba no reflejaba con lo que observaba la gente y los periodistas de algunos medios de comunicación.

Igualmente, se comunicó que ya se habían subscritos convenios con laboratorios farmacéuticos que fabrican las vacunas contra el Covid-19; sin embargo, al parecer esto tampoco fue cierto, mientras que a países vecinos ya les están llegando los primeros lotes de la vacuna. Todo esto se agravó por la crisis política que el Perú vivió en la primera quincena del mes de noviembre con la vacancia primero, del presidente Martín Vizcarra y luego, del presidente Manuel Merino, quien finalmente fue remplazado por el presidente Francisco Sagasti.

En una pandemia, el acceso a una información concisa y verídica es un tema de vida o muerte.
La población tiene el derecho a informarse sobre las medidas de salud, las estadísticas transparentes y las determinaciones que toman los gobernantes.

La salud no solo depende de la atención médica cómodamente asequible sino también del acceso a datos precisos sobre el origen de las amenazas y los medios disponibles para cuidarse a uno mismo, la familia y la comunidad.

Los rumores se comprueban mucho mejor al garantizar el acceso a fuentes de información pluralistas e independientes. Los gobernantes no ganan mucha confianza del pueblo si notan que intentan esconder información o limitar a los medios de comunicación. Es así que, en vez de más restricciones, se requiere más transparencia.

En lugar de callar a los hombres de prensa, los mandatarios tendrían que permitirles realizar su labor sin impedimentos y autorizarles a localizar y emplear todas las fuentes que los propios medios estimen necesarias.

En consecuencia, los mandatarios deberían brindar datos confiables a los periodistas. Además, es necesario que apoyen económicamente a los medios de comunicación que informan sobre los efectos de la pandemia y cómo la población la debería prevenir o combatir. Por otra parte, se deberá tener en consideración que el trabajo periodístico no debería bajar ni desaparecer en los próximos años.

La libertad de expresión e información, combinada con un horizonte pluralistas, son contribuyentes trascendentales del desarrollo económico, y son también mecanismos decisivos para fortalecer las afinidades sociales y las estructuras de democracia. 


\section{El periodismo en tiempos de pandemia}

Desde el 16 de marzo del 2020, fecha de la irrupción de la Covid-19 en el Perú, agravó muchas de las situaciones que desde hace algunos años perjudicaban el ejercicio del periodismo peruano. La existencia de datos sobre la embestida del virus, fueron abundantes e inconstante, que requirió tamizarlos oportuna y adecuadamente. A los hombres de prensa le correspondió comprobarlos, interpretarlos e informarlos, ya que ellos tienen la labor de guiar a los ciudadanos a afrontar la coyuntura diaria durante la pandemia, más aún sabiendo que algunos peruanos tienen la costumbre de automedicarse. O sea, pues, que el rol del periodismo es transcendental en tiempos de pandemia.

Es válido decir que existió abundantes datos y la labor de los periodistas fue más difícil, ya que los posibles lectores ya tenían una información previa. Sin embargo, en muchas ocasiones los ciudadanos no estaban seguros si la información era o no cierta. En esta circunstancia los periodistas hacían las aclaraciones y explicaciones del caso.

Si bien existía muchos datos disponibles y los ciudadanos estructuraban su propia agenda de datos, los periodistas investigaban los datos que tenían las personas, y los comprobaba para que esa información tenga veracidad y sea de utilidad.

Asimismo, es importante indicar que en tiempos de pandemia los hombres de prensa tienen una esencial y relevante labor, ya que ellos difunden los hechos que ocurren durante la misma. Tienen un rol que consiste en brindar información clave sobre la salud a la población y en modificar la jerga científica en un lenguaje que una persona de a pie pueda comprender.
Trabajo Del Periodismo ImPReso EN TIEMPOS DE PANDEMIA

\section{Adaptación al teletrabajo}

En el Perú, debido a la pandemia de la COVID-19, los medios de comunicación, han tenido que encontrar, en técnicas de adecuación, la condición más adecuada para continuar con el desarrollo de sus actividades de la manera más normal posible o, dicho de otra forma, sin detener el flujo de información. La pandemia de la Covid-19 ha exigido a muchos periódicos a incursionar en la tecnología digital con redacciones móviles y de teletrabajo. Aunque este cambio no se esperaba de manera rápida, los periódicos han tenido que adecuarse a la coyuntura.

Para medios convencionales como son la radio, la prensa escrita y televisiva, este mecanismo los ha forzado a instaurar el trabajo a distancia en la mayor parte de casos, y puede ser mucho más desafiante que para los medios de webs, cuyas dinámicas están más familiarizadas con lo digital. Es importante que, en tiempos difíciles como el que estamos viviendo, los medios de comunicación deben adaptarse a mecanismos útiles para poder informar de una manera eficaz y eficiente.

Por la naturaleza del medio en el que se labora -periodismo escrito- la calidad de las imágenes es uno de los ejes centrales, y la determinación de escribir desde sus hogares notas periodísticas anexadas con imágenes era realmente un gran desafío.

El periodista trabajando en su hogar, muchas veces tiene cierta dificultad en su quehacer, especialmente en editar imágenes de calidad necesarias para corroborar o aclarar la noticia; por este motivo, en varios medios impresos se tuvo la necesidad de replantear la labor 
periodística y ver la manera de reducir lo más posible la asistencia de los periodistas en redacción, y solo quedarse con el equipo esencial que se necesita.

El mecanismo empleado por el diario La República es tener un grupo de redactores que realizan solo notas desde sus hogares de manera simultánea, mientras que un grupo de reporteros están en el campo realizando cobertura durante todo el día.

En tiempo de pandemia es conveniente que los reporteros tengan dos o tres días libres para que puedan descansar y estar menos expuestos al contagio del coronavirus.

El personal administrativo y de servicios generales cuya presencia es necesaria en el local institucional tiene que asistir y permanecer según el horario establecido, pero cumpliendo con los protocolos de bioseguridad para salvaguardar su salud.

\section{Rutinas y horarios de trabajo}

La rutina de la labor periodística cambió considerablemente. Los encargados de la edición se mantenían activos desde las seis de la mañana, cotejando datos y observando lo que estaba aconteciendo en diferentes partes del mundo; luego, mediante video conferencia que estaba programada a las ocho de la mañana, consensuaban la información para hacerla conocer al público.

En el diario La Industria de Trujillo, conjuntamente con las medidas preventivas de bioseguridad que se implementó según las recomendaciones de la OMS, se modificaron los horarios de los periodistas con la finalidad de que se mantengan las mayores horas posibles en sus hogares, evitando así salir y estar expuestos al contagio de la enfermedad.
Antes de la pandemia descansaban dos días por semana; luego decidieron agregar dos días más de descanso; los demás días los dedicaban continuamente a cumplir sus funciones.

Antes de la pandemia de la Covid-19, los periodistas en sus días libres (días de descanso) obviamente no trabajaban; pero, a los que se quedaban en redacción el trabajo se les recargaba. Hoy en día, que estamos en tiempo de pandemia, el trabajo de redacción se puede hacer desde casa; pero esta situación no es del todo buena ya que puede haber limitaciones o contratiempos como, por ejemplo, la accesibilidad a red, no tener una computadora idónea, o no tener el contacto necesario para realizar alguna coordinación.

El movimiento de los corresponsales de los medios de comunicación escrito únicamente se realiza cuando es imprescindible la presencia de ellos para informar algunos acontecimientos que producían la pandemia.

\section{IMPACTO SOCIOECONÓMICO DEL PERIODISMO} ESCRITO EN TIEMPOS DE PANDEMIA

\section{Decesos de periodistas}

La pandemia de la Covid-19 ha develado la pésima situación de trabajo de muchos periodistas que están informando desde la primera línea de lucha contra ese terrible mal; igualmente ha mostrado las deplorables condiciones de protección sanitaria que sus empleadores les brindan.

La ANP (4) informó que, en doscientos días de pandemia, es decir desde el 16 de marzo en el que el gobierno peruano decretó emergencia nacional, hasta el primero de octubre, han fallecido 163 periodistas. De estos, 92 fallecieron como consecuencia del coronavirus (39 contagiados cumpliendo su 
labor informativa); y 71 murieron, en el marco de la pandemia, por otras enfermedades. De los periodistas que murieron por la Covid-19, la mayoría adquirió el temible virus en los nosocomios o mercados de abastos, que son focos altamente contagiosos. La ANP mediante un comunicado informó, la noche del miércoles 1 de abril, el fallecimiento a causa de la Covid-19 del primer periodista peruano. Su fallecimiento ocurrió en el Hospital Nacional Edgardo Rebagliati Martin en la ciudad de Lima.

A estos números hay que agregar 14 trabajadores fallecidos como, por ejemplo, administradores, conductores, locutores, etc.

Del total de decesos, la mayor cantidad han sido de la provincia de Lima con 46 casos; seguida de Iquitos con 9; luego Cuzco con 8, Arequipa con 7, El Santa con 6; Después Chincha, Huamanga, Huaraz y Trujillo tienen 5 casos cada una; y por último Piura, Puno y Tumbes y con 4 decesos cada una.

\section{Despidos masivos}

El coronavirus mostró lo que diversos medios de comunicación no refieren: la precariedad laboral de los hombres de prensa y el atropello de los directivos.

En el Perú, muchos periodistas han sido masivamente despidos de sus centros de labores, o les han disminuido sus salarios. Según la Asociación Nacional de Periodistas del Perú (ANP) (4), hasta el primero de octubre, quinientos colaboradores de medios de comunicación han sido despedidos de su centro de trabajo.

El Grupo El Comercio, que está constituido por el diario Trome, El Comercio, Perú 21, Gestión, Correo y otros, redujo los salarios de sus colaboradores en un $30 \%$ durante los meses de mayo, junio y julio; posteriormente perdieron su trabajo 300 colaboradores, incluyendo a los que salieron por clausura definitiva del Publimetro y de la edición impresa del diario de deportes Bocón.

El Grupo La República, que posee diarios como El Popular, La República y otros, fueron cesados de su trabajo 60 periodistas a consecuencia de la pandemia del Covid-19.

En tanto, la Corporación Universal (que está conformado por los periódicos Exitosa y Karibeña) y algunos radios y canales de televisión, adeudan meses de sueldos y sus beneficios sociales han sido postergados.

También hay que referir que el 19 de octubre, en el marco de la pandemia de la Covid-19, la revista semanal Caretas que fue fundada a fines de agosto de 1950, cierra sus puertas y deja de ser publicada. La Editora Novolexis SAC razón social con la que se edita la revista Caretas, el 7 de octubre, mediante carta notarial hace de conocimiento a sus trabajadores la liquidación de la misma, y que solo trabajarían hasta el 19 de octubre. (6) Después de haber pasado por muchos años de éxito editorial, el tiraje de la revista fue disminuyendo y su importancia en la opinión pública también disminuyó notablemente. Dos años antes que cierre Caretas, su planilla era de 100 trabajadores, al cerrar solo contaba, según la SUNAT con 23 trabajadores. La decadencia paulatina que experimentó la revista en el transcurso de los últimos años, se agudizó con la venida de la pandemia del Covid-19; sin embargo, considero que no fue la causa principal del cierre.

Los periodistas de provincias fueron los mayores perjudicados por la pandemia del Covid-19, ya que 10 diferentes medios de comunicación se vieron obligados a cerrar 
debido a la falta de ingresos por publicidad, o recortar su propuesta informativa, dejándolos a muchos sin empleo.

El detenimiento de actividades económicas y productivas, por más de quince semanas, ha afectado considerablemente a los diarios, que tenían una situación crítica, por varios motivos, antes de la pandemia.

\section{Agresiones a periodistas}

Otra situación preocupante en el Perú ha sido las agresiones a periodistas y a medios de comunicación durante la pandemia de la Covid-19. Desde el 16 de marzo hasta el primero de octubre del presente año, la ANP (4) registró 109 agresiones a periodistas y medios de comunicación. Cifra que supera largamente a los ataques que se registraron durante todo el año 2019.

A continuación, se detalla las cifras de ataques a periodistas y medios de comunicación que ha reportado la Asociación Nacional de Periodistas del Perú 4

Entre los ataques más comunes destaca la amenaza y hostigamiento, con 28 casos registrados; seguido por trabas al acceso a la información con 18 casos y por agresiones físicas y verbales también con 18 casos. Le siguen la intimidación judicial en 12 casos. También se han presentado ciberataques (10 casos), discurso estigmatizante (10 casos), detenciones (5 casos), presiones y sanciones administrativas (4casos) y robos (4 casos).

Entre los agresores identificados están: agentes de seguridad (policías, militares, serenazgo, vigilante), que han ocasionado 39 ataques, le siguen los funcionarios (28 casos), civiles (24 casos) y empleadores (7 casos). Hubo 11 casos que no se pudo identificar a los agresores.

\section{Venta y producción de periódicos}

Castigados por el cataclismo económico y social desatada por la pandemia de la Covid-19, los diarios afrontaron nuevos y difíciles retos que trajo a la mente nuevas interrogantes relacionadas con su porvenir y con el negocio, que muchos expertos consideran agotado.

El coronavirus igualmente afectó la producción en número de páginas por periódico. Antes de la invasión de la Covid-19 los diarios empleaban 36 páginas para informar; hoy el diario La Industria de Trujillo utiliza alrededor de veinte a veinticuatro páginas. Con esa disminución se ha conseguido que los colaboradores permanezcan menos tiempos en su centro de labores y, en consecuencia, menos expuestos al contagio de la enfermedad.

A pesar de la reducción de páginas, la venta del periódico ha sido mejor de lo estimado. Al comienzo de la pandemia parecía desalentador; pero, conforme transcurrían los días, la venta del periódico ha sido buena, situación que fehacientemente ha comprobado que existe un valor en la información regional.

Se cree que el número lectores de diarios peruanos llegó a un $73 \%$ durante el estallido de la crisis, es decir en la segunda semana de marzo del presente año, y en periódicos como La República y El Comercio alcanzaron registros históricos.

La tendencia por encontrar información igualmente se evidenció en la red. Según la Comscore, los ingresos a periódicos y otros medios de información en línea de nuestro país se quintuplicaron en la tercera semana de marzo, con cuatrocientos cincuenta millones entradas en páginas de noticias. 
A juzgar por el despido de periodistas dela prensa escrita o por la disminución de sus salarios, señalados líneas arriba, es lógico pensar que las ventas de los periódicos y los lectores posteriormente disminuyeron por razones económicas. No se ha encontrado información de este hecho en los medios de comunicación; pero, es vox pópuli la disminución de la venta de los periódicos y de los lectores. Todo hace pensar que ese público ahora sólo se está informando de la pandemia de la Covid-19 mediante la televisión o la radio. La publicidad en tiempos de Covid

En relación a la publicidad durante la pandemia del Covid-19, es importante mencionar dos factores que en el Perú han acontecido:

En primer lugar, hubo la decisión, al parecer equivocada, de suprimir el cobro de la información sobre la pandemia. Suscitó confusión entre la vocación de servicio, la urgencia por ser "el más actualizado" y la exigencia de dar material de calidad, que se distinga notoriamente sobre las "fake news", han restado a los medios de comunicación el chance de fidelizar a los consumidores y obtener suscripciones que ayuden a la viabilidad económica.

En segundo lugar, está el declive o caída de la publicidad, debido a que las empresas que frecuentemente anunciaban en los periódicos, carecían de recursos económicos para invertir en publicidad. Tendencia que aumentó a medida que la pandemia se agravó y prolongó. En muchos lugares del Perú, la necesidad de sobrevivir condujo a adoptar soluciones de urgencia como, por ejemplo, disminuir el tiraje de la impresión

En este contexto, los ingresos de dinero por suscriciones a los medios de comunicación atenuaron los bajos ingresos por publicidad, ya que los suscritores a los medios de comunicación aumentaron, ya sea para que el periódico les llegue en físico a las casas o para tener acceso a los periódicos on line.

\section{Conclusiones}

El gobierno peruano no sinceró oportunamente la cifra de los contagiados y muertes durante el tiempo de pandemia. También ha mostrado impericia, pues hasta la fecha no ha firmado contratos con laboratorios farmacéuticos para la adquisición de las vacunas.

El periodismo en tiempos de pandemia tiene un esencial y relevante rol ya que brinda información clave sobre la salud y la enfermedad que ocurren durante la misma; modifica la jerga científica en un lenguaje que una persona de a pie pueda comprender para que le sea útil y pueda afrontar la coyuntura diaria.

Se incursionó rápidamente a la tecnología digital, y la dinámica de trabajo cambió drásticamente. Se modificaron los horarios de trabajo con el fin de que un gran porcentaje de periodistas se encuentra en sus casas realizando sus labores y solo el personal necesario se encuentra cubriendo notas en las calles siguiendo todos los protocolos de bioseguridad.

Ciento sesenta y tres periodistas murieron durante la pandemia De ésta cifra, 92 murieron a consecuencia del Covid-19 (39 contagiados cumpliendo su labor informativa); y 71 murieron, en el marco de la pandemia, por otras enfermedades.

Quinientos trabajadores de prensa fueron despedidos de su centro de labores; y a muchos les disminuyeron su sueldo. 
Se registró ciento nueve agresiones a periodistas y a medios de comunicación.

Si bien la producción, en relación al número de páginas, disminuyó, la venta de periódicos se elevó en los primeros meses de la pandemia, debido a la necesidad de los lectores de obtener información actualizada; pero, posteriormente, disminuyo por la situación económica de la gente.

La publicidad experimentó cambios negativos debido a que suprimieron los segmentos pagados, registrándose menos anunciantes.

\section{REFERENCIAS BIBLIOGRÁficAS}

1. News Coronavirus disease named Covid-19, BBC News, 11 febrero 2020. URL disponible en https://www.bbc.com/ news / world-asia-china-51466362

2. Organización Mundial de Salud. Nuevo Coronavirus en China, 12 enero 2020. URL disponible en: https: / / www.who.int/ csr/ don/12-january-2020-novel-coronavirus-china/es/

3. Instituto Nacional de Salud y Centro Nacional de Epidemiología, Prevención y Control de Enfermedades MINSA. Sala Situacional Covid-19 Perú, Ministerio de Salud, 24 de diciembre 2020. URL disponible en: https:// covid19.minsa. gob.pe/sala_situacional.asp

4. Saldaña Pía. Periodismo peruano: adaptarse en tiempos de COVID-19. Instituto de Prensa y Sociedad (IPYS), 13 de abril 2020. Disponible en: https://ipys.org/noticias/ periodismo/ periodismo-peruano-adaptarse-en-tiempos-decovid-19

5. Instituto Prensa y Sociedad (IPYS). Día del Periodista Peruano: La ANP informa sobre 163 muertes, 109 ataques y al menos medio millar sin empleo. 1 de octubre 2020. URL disponible en: https: / /ipys.org/noticias/periodismo/dia-del-periodistaperuano-anp-informa-sobre-163-muertes-109-ataques-y-almenos-medio-millar-sin-emple

6. Marchán Eloy. Caretas, la legendaria revista de Enrique Zileri, entra en proceso de liquidación. El Foco, 8 de octubre 2020. URL disponible en : https://elfoco.pe/informes/caretas-lalegendaria-revista-de-enrique-zileri-entra-en-proceso-deliquidacion/

7. Dirconfidencial. Las suscripciones a diarios digitales se multiplican durante la pandemia, Abril 2020. URL disponibleen: https: / / dircomfidencial.com/medios/las-suscripciones-adiarios-digitales-se-multiplican-durante-lapandemia-20200415-0405/

\section{CORRESPONDENCIA}

\section{Emiliano Paico Zumaeta}

epaicoz1@upao.edu.pe

Fecha de recepción: 25-12-2020.

Fecha de aceptación: 11-01-2021.

Conflicto de interés: ninguno, según el autor.

Financiamiento: por el autor. 